\title{
A superficial esophageal cancer in an epiphrenic diverticulum treated by endoscopic submucosal dissection
}

\author{
Kuangi $\mathrm{Fu}^{1,2^{*}}$, Peng $\mathrm{Jin}^{2}$, Yuqi He${ }^{2}$, Masanori Suzuki ${ }^{1}$ and Jianqiu Sheng ${ }^{2}$
}

\begin{abstract}
Background: We report a unique case of a superficial esophageal cancer arising in a single diverticulum, diagnosed with magnifying image-enhanced endoscopy and then successfully treated by endoscopic submucosal dissection (ESD).

Case presentation: A 66-year-old man with alcohol-related liver injury visited our hospital for endoscopy for investigation of varix. Esophagogastroduodenoscopy showed no varix but a large epiphrenic diverticulum with an area of fainted redness just above the esophagogastric junction. Narrow band imaging revealed a sharply demarcated brownish dotted area, and dilated intra-epithelial papillary capillary loops (IPCL) were subsequently seen after magnification. Chromoendoscopy with 1\% Lugol's iodine solution demonstrated a well-demarcated unstained area, approximately $20 \mathrm{~mm}$ in diameter. Endoscopic biopsy revealed a squamous cell carcinoma (SCC).

Conclusion: The tumor was completely resected by ESD without perforation. Histologically, it was an intraepithelial SCC without lympho-vascular invasion of cancer cells. No local recurrence or metastasis was detected at the last follow-up of 42 months.
\end{abstract}

Keywords: Epiphrenic diverticulum, Superficial esophageal cancer, Magnifying endoscopy, Narrow band imaging, Endoscopic submucosal dissection

\section{Background}

Cancer can arise from the normal mucosa near or within an esophageal diverticulum. However, cancer located within a diverticulum is a very rare phenomenon; only sporadic cases have been reported to date. The incidence has been reported to be between 0.3 and 3\% [1]. Almost all cases were diagnosed at an advanced stage, treated by surgery or radiation, and with overall poor prognosis. Rarely cases are detected in early stage and surgical resection is favored as diverticula have a characteristically thin wall and endoscopic resection carries a real risk of perforation [2]. Herein, we describe a case of a superficial esophageal cancer developed in an epiphrenic esophageal diverticulum, diagnosed with magnifying image-enhanced endoscopy and subsequently treated by endoscopic submucosal dissection (ESD).

\footnotetext{
* Correspondence: fukuangi@hotmail.com

${ }^{1}$ Department of Gastroenterology, Kanma Memorial Hospital, 2-5,

Nasushiobara city, Tochigi 325-0046, Japan

${ }^{2}$ Department of Gastroenterology, PLA Army General Hospital, Beijing 100700, China
}

\section{Case presentation}

A 66-year-old man with alcohol-related liver injury visited our hospital for endoscopy for investigation of varix. Esophagogastroduodenoscopy (Olympus; Japan) showed no varix but a large epiphrenic diverticulum just above the esophagogastric junction (Fig. 1a). An area of fainted redness was detected with white light endoscopy at the base of the diverticulum (Fig. 1b). Narrow band imaging (NBI) endoscopy (GIF-H260Z, Olympus) revealed a demarcated brownish dotted area (Fig. 2a). Dilated intra-epithelial papillary capillary loops (IPCL) classified as B1 according to Japan Esophageal Society classification were subsequently seen on magnification (Fig. 2b) [3, 4]. Chromoendoscopy with $1 \%$ Lugol's iodine solution demonstrated a well-demarcated unstained area, approximately $20 \mathrm{~mm}$ in diameter, corresponding to the reddish area (Fig. 3). Pink color sign was also seen in the unstained area about $2 \mathrm{~min}$ after iodine staining [5]. Endoscopic biopsy revealed a squamous cell carcinoma (SCC). The depth of invasion of the detected 

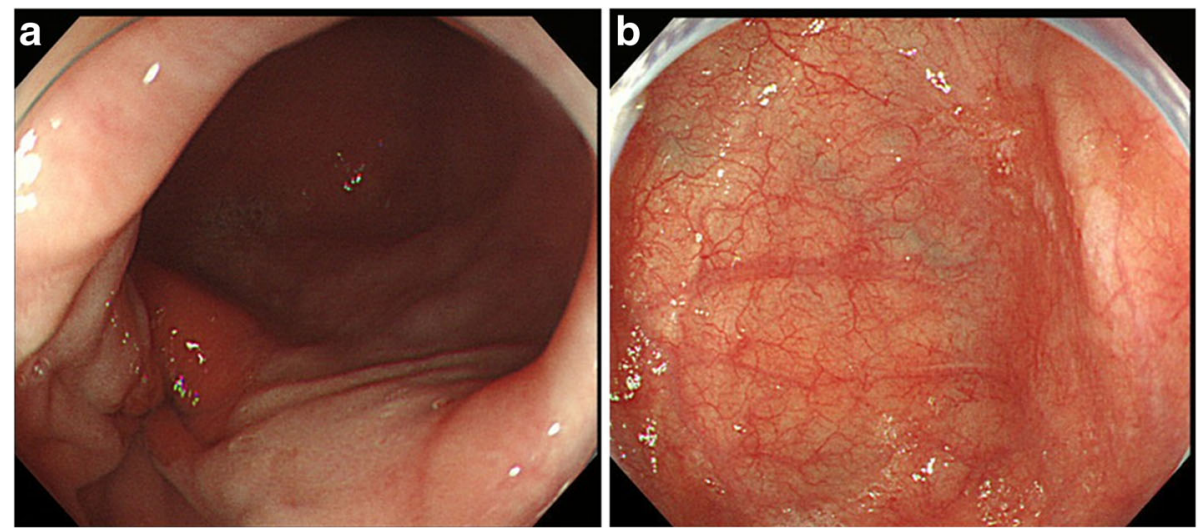

Fig. 1 a A large epiphrenic diverticulum just above the esophagogastric junction was seen during esophagogastroduodenoscopy. b An area of fainted redness was detected with white light endoscopy at the bottom of the diverticulum

tumor was estimated to remain within the mucosal epithelium (m1) or the lamina propria (m2), which carries almost no potential for nodal involvement. Therefore, ESD was proposed as an alternative to radical surgery and patient consent was obtained. Endoscopic submucosal dissection was conducted with the patient under general anesthesia. $\mathrm{CO} 2$ was used for insufflation to decrease the risk of mediastinal emphysema or pneumothorax in the event of perforation. The lesion was well-lifted after submucosal injection of hyaluronic acid diluted with $10 \%$ glycerol at the ratio of $50 \%$. The tumor was completely resected en bloc without complication (Fig. 4). Histologically, the resected specimen was a superficial cancer limited within the lamina propria $(\mathrm{m} 2)$ without lympho-vascular invasion or marginal involvement of cancer cells. The patient had an uneventful hospital course and was discharged 1 week after ESD. No local recurrence or metastasis was detected at the last follow-up of 42 months (Fig. 5).

\section{Discussion and conclusions}

Cancers arising within esophageal diverticulum may be diagnosed at advanced stage despite their small size. As the muscular coat of a diverticulum is extremely thin or none, cancer arising within an esophageal diverticulum can easily extend into the mediastinal space relative to those arising from the normal mucosa apart from the diverticulum. This case was easily detected with the help of magnifying image-enhanced endoscopy in its early stage [3]. Our case illustrates the importance of meticulous endoscopic evaluation of depth invasion of esophageal cancers before removal, as surgery may be avoided in some cases. The changes in the IPCL pattern observed by magnifying NBI were reported to be useful for the qualitative diagnosis of cancerous/non-cancerous lesions and endoscopic diagnosis of invasion depth of cancers $[6,7]$. Here we performed endoscopic resection of the lesion, as magnifying image-enhanced endoscopy provided an endoscopic diagnosis of a superficial cancer limited within the lamina propria $(\mathrm{m} 2)$. It is commonly
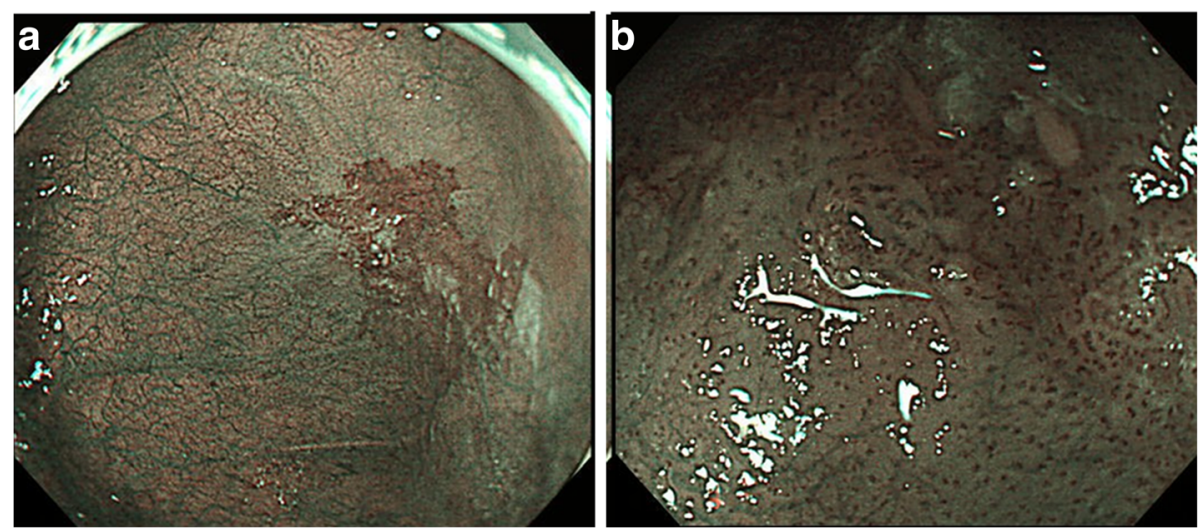

Fig. 2 a NBI revealed a demarcated brownish dotted area before magnification. b Dilated intra-epithelial papillary capillary loops (IPCL) were seen after magnifying NBI 


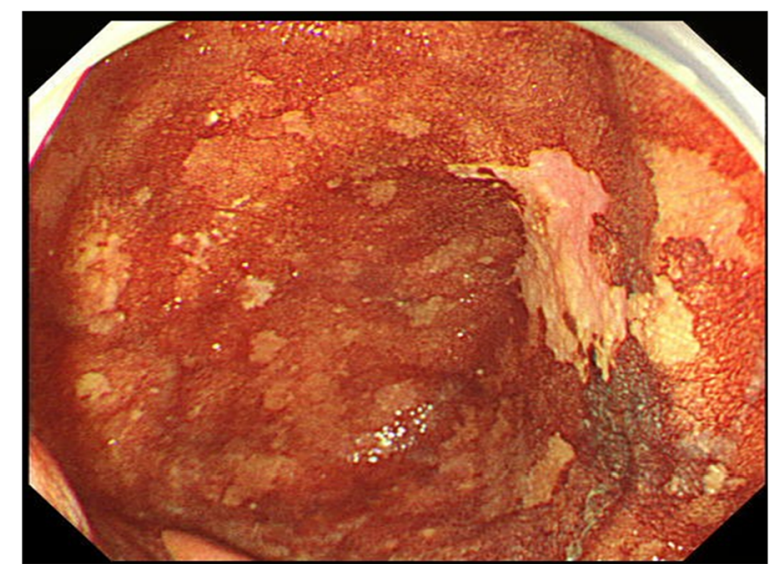

Fig. 3 At the bottom of the diverticulum, chromoendoscopy with $1 \%$ Lugol's iodine solution demonstrated a well-demarcated unstained area, approximately $20 \mathrm{~mm}$ in diameter

accepted that esophageal cancers limited within $\mathrm{m} 2$ are extremely rarely associated with lymph node metastasis and therefore are good candidates for endoscopic resection [8].

Endoscopic ultrasonography (EUS) is commonly used for predicting the depth of tumor invasion in patients with superficial esophageal squamous cell carcinoma [9]. We did not utilize EUS in this case as part of the diagnostic workup, as it was difficult to appropriately approach the lesion located at the base of the diverticulum. Furthermore, diverticulum has a characteristically thin wall, which may be associated with higher risk of perforation during EUS [10].

Endoscopic mucosal resection (EMR) might be an alternative for local resection. There are three representative methods of EMR: endoscopic esophageal mucosal resection (EEMR)-tube method, EMR using a cap-fitted endoscope (EMRC) method and two-channel EMR

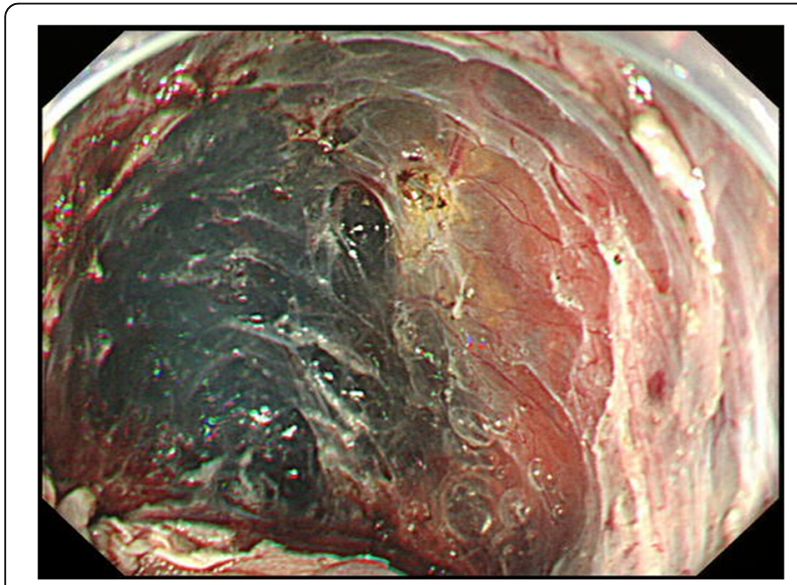

Fig. 4 Mucosal defect after ESD was shown and no definite perforation was seen endoscopically

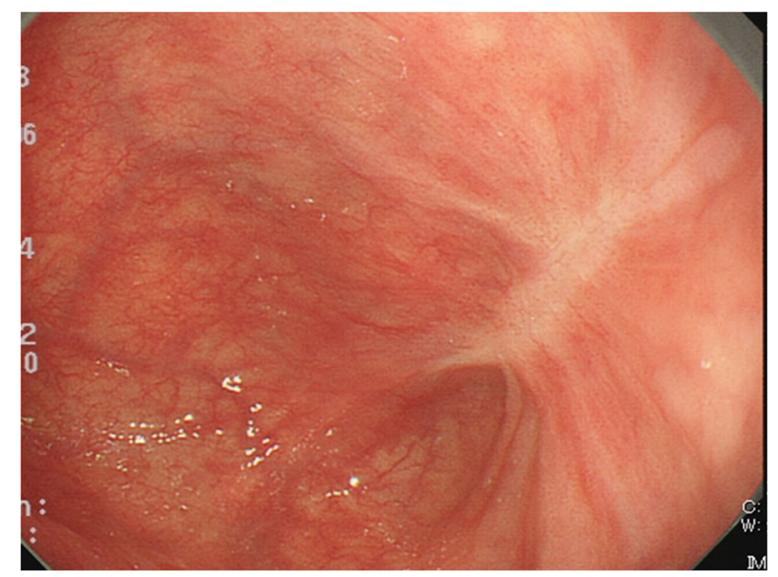

Fig. 5 White light endoscopy showed no local recurrence 42 months after ESD

method. Generally, the incidence of perforation is lower than that of ESD. However, the lesion described here was not amenable to EMR as pulling the lesion back for resection would have resulted in frank perforation, likely $10 \mathrm{~mm}$ or larger in size, making endoscopic closure technically very difficult. Meanwhile, perforation during ESD is always smaller and linear, as the submucosal layer could be dissected under direct visualization [11]. To avoid undesirable perforation, we therefore planned to discontinue ESD if non-lifting sign positive was seen after appropriate submucosal injection. To achieve an appropriate submucosal dissection plane under the tumor for complete removal, mucosal incision and submucosal dissection were started from the oral side of the normal mucosa outside of the diverticulum as both of the submucosal and muscular layers of the diverticulum were expected to be much thinner than those of the normal esophagus histologically.

In conclusion, we report a case of a superficial esophageal cancer developing within an epiphrenic diverticulum. The lesion was correctly diagnosed with magnifying image-enhanced endoscopy and subsequently treated by ESD with long-term success.

\section{Acknowledgements}

We thank Dr. Dhavan Parikh (UC Davis Medical Center) for initial editing of this manuscript.

\section{Funding}

This work was supported by Capital city public health project (Grant No. Z141100002114007).

Availability of data and materials

All data analysed during this study are included in this published article and its supplementary information files.

\section{Authors' contributions}

Concept of the manuscript- KF; lesion detection and ESD procedure- KF; literature review of the manuscript- MS; writing of the manuscript- KF, PJ, YH, JS; all authors have read and approved the final version of the manuscript. 


\section{Ethics approval and consent to participate}

Written consent was obtained from the patient. As a case report, approval from the institutional review board was not needed.

\section{Consent for publication}

Written informed consent was obtained from the patient for publication of this case report.

\section{Competing interests}

The authors declare that they have no competing interests.

\section{Publisher's Note}

Springer Nature remains neutral with regard to jurisdictional claims in published maps and institutional affiliations.

Received: 28 April 2017 Accepted: 31 July 2017

Published online: 07 August 2017

\section{References}

1. Benacci JC, Deschamps C, Trastek VF, Allen MS, Daly RC, Pairolero PC. Epiphrenic diverticulum: results of surgical treatment. Ann Thorac Surg. 1993:55:1109-13.

2. Honda H, Kume K, Tashiro M, Sugihara Y, Yamasaki T, Narita R, et al. Early stage esophageal carcinoma in an epiphrenic diverticulum. Gastrointest Endosc. 2003;57:980-2.

3. Muto M, Minashi K, Yano T, Saito Y, Oda I, Nonaka S, et al. Early detection of superficial squamous cell carcinoma in the head and neck region and esophagus by narrow band imaging: a multicenter randomized controlled trial. J Clin Oncol. 2010;28:1566-72.

4. Oyama T, Inoue H, Arima M, Momma K, Omori T, Ishihara R, et al. Prediction of the invasion depth of superficial squamous cell carcinoma based on microvessel morphology: magnifying endoscopic classification of the Japan esophageal society. Esophagus. 2017;14:105-12.

5. Shimizu Y, Omori T, Yokoyama A, Yoshida T, Hirota J, Ono Y, et al. Endoscopic diagnosis of early squamous neoplasia of the esophagus with iodine staining: high-grade intra-epithelial neoplasia turns pink within a few minutes. J Gastroenterol Hepatol. 2008:23:546-50.

6. Kumagai $Y$, Inoue H, Nagai K, Kawano T, Iwai T. Magnifying endoscopy, stereoscopic microscopy, and the microvascular architecture of superficial esophageal carcinoma. Endoscopy. 2002;34:369-75.

7. Sato $H$, Inoue $H$, Ikeda $H$, Sato $C$, Onimaru M, Hayee $B$, et al. Utility of intrapapillary capillary loops seen on magnifying narrow-band imaging in estimating invasive depth of esophageal squamous cell carcinoma. Endoscopy. 2015:47:122-8.

8. Takubo K, Aida J, Sawabe M, Kurosumi M, Arima M, Fujishiro M. Early squamous cell carcinoma of the oesophagus: the Japanese viewpoint. Histopathology. 2007;51:733-42.

9. Yoshinaga S, Oda I, Nonaka S, Kushima R, Saito Y. Endoscopic ultrasound using ultrasound probes for the diagnosis of early esophageal and gastric cancers. World J Gastrointest Endosc. 2012:4:218-26.

10. ASGE Standards of Practice Committee, Early DS, Acosta RD, Chandrasekhara V, Chathadi KV, Decker GA, Evans JA. Adverse events associated with EUS and EUS with FNA. Gastrointest Endosc. 2013:77:839-43.

11. Oyama T. Esophageal ESD: technique and prevention of complications. Gastrointest Endosc Clin N Am. 2014:24:201-12.

\section{Submit your next manuscript to BioMed Central} and we will help you at every step:

- We accept pre-submission inquiries

- Our selector tool helps you to find the most relevant journal

- We provide round the clock customer support

- Convenient online submission

- Thorough peer review

- Inclusion in PubMed and all major indexing services

- Maximum visibility for your research

Submit your manuscript at www.biomedcentral.com/submit
Biomed Central 